\title{
Tensile strength assay comparing the resistance between two different autologous platelet concentrates (leucocyte-platelet rich fibrin versus advanced-platelet rich fibrin): a pilot study
}

Martim de Almeida Nóbrega Correia Pascoal ${ }^{1}$, Nuno Bernardo Malta dos Santos² ${ }^{2}$, António Manuel Godinho Completo ${ }^{3}$ (D) and Gustavo Vicentis de Oliveira Fernandes ${ }^{2,4^{*}}$ (i)

\begin{abstract}
Background: Since the leucocyte-platelet rich fibrin (L-PRF) was published in 2001, many studies have been developed, analyzing its properties, and also verifying new possibilities to improve it. Thereby, it emerges the advanced-platelet rich fibrin (A-PRF) with a protocol that optimizes the properties obtained by the L-PRF. Nonetheless, there is a gap in the literature to landmark the evolutive process concerning the mechanical properties in specific the resistance to tensile strength which consequently may influence the time for membrane degradation. Thus, this study had the goal to compare the resistance to the traction of membranes produced with the original L-PRF and A-PRF protocols, being the first to this direct comparison.

Findings: The harvest of blood from a healthy single person, with no history of anticoagulant usage. We performed the protocols described in the literature, within a total of 13 membranes produced for each protocol $(n=$ 26). Afterward, the membranes were prepared and submitted to a traction test assessing the maximal and the average traction achieved for each membrane. The data were analyzed statistically using the unpaired $t$ test. Regarding average traction, A-PRF obtained a value of $0.0288 \mathrm{~N} \mathrm{~mm}^{-2}$ and L-PRF $0.0192 \mathrm{~N} \mathrm{~mm}^{-2}(p<$ 0.05 using unpaired $t$ test). For maximal traction, A-PRF obtained $0.0752 \mathrm{~N} \mathrm{~mm}^{-2}$ and L-PRF $0.0425 \mathrm{~N} \mathrm{~mm}^{-2}(p$ $<0.05$ using unpaired $t$ test).

Conclusion: With this study, it was possible to conclude that indeed A-PRF has a significative higher maximal traction score and higher average traction compared to L-PRF, indicating that it had a higher resistance when two opposing forces are applied.
\end{abstract}

Keywords: Fibrin, Rupture, Platelet, Tensile strength, Resistance

\footnotetext{
* Correspondence: gustfernandes@gmail.com
2Periodontics Department, Center for Interdisciplinary Research in Health (CIIS), Faculty of Dental Medicine, Universidade Católica Portuguesa, Viseu, Portugal

${ }^{4}$ Implantology and Biomaterials Department, Faculty of Dental Medicine,

Universidade Católica Portuguesa, Quinta da Alagoa Ave., 225 - 1 DT,

3500-606 Viseu, Portugal

Full list of author information is available at the end of the article
}

\section{Springer Open}

(c) The Author(s). 2021 Open Access This article is licensed under a Creative Commons Attribution 4.0 International License, which permits use, sharing, adaptation, distribution and reproduction in any medium or format, as long as you give appropriate credit to the original author(s) and the source, provide a link to the Creative Commons licence, and indicate if changes were made. The images or other third party material in this article are included in the article's Creative Commons licence, unless indicated otherwise in a credit line to the material. If material is not included in the article's Creative Commons licence and your intended use is not permitted by statutory regulation or exceeds the permitted use, you will need to obtain permission directly from the copyright holder. To view a copy of this licence, visit http://creativecommons.org/licenses/by/4.0/. 


\section{Introduction}

The most frequently used biomaterial are the ones that come from autologous sources, which is still and considered to be the "gold standard" due to all its properties, including induction, conduction, and genesis, besides preventing the risk of infection [1]. These biomaterials can be produced from hard or soft tissue (e.g., bone and connective tissue, respectively), or the blood. In the past years, autologous blood concentrates have been traditionally used in transfusions aiding in the control of hemorrhage caused by severe thrombocytopenia, often associated with multiple blood illnesses or because of blood loss during long surgeries [2].

Historically, there are three generations of autologous platelet concentrates (APCs). The first was mainly represented by platelet-rich plasma (PRP) that was produced with the introduction of an anticoagulant (sodium citrate, EDTA) and other compounds (calcium chloride, bovine thrombin) in the collection tubes and it required two centrifugations. This product has shown to be useful on certain occasions as the literature has shown [3].

Other APCs are described as fibrin glues (used to seal wounds and promote healing) [3], the platelet gel [4]. And plasma rich in growth factors (PRGF) [5] which required not only the addition of an anticoagulant but also of calcium chloride, to activate platelets resulting in the release of growth factors [6]. However, the PRGF protocol proved to be problematic due to its lack of reproducibility and leading to a greater possibility of obtaining undesirable tissue response $[5,7]$.

The second generation was introduced in 2001 with a smaller cost of production, easier handling, and better success rates in clinical cases $[1,8,9]$, represented primarily by leucocyte-platelet rich fibrin (L-PRF), which were able to create a superior scaffold [10]. This material was produced in a dry tube with no added compounds within it. Biochemical analysis of the PRF indicates that this biomaterial consists of the presence of cytokines, glycan chains, and structural glycoproteins involved in the fibrin network that was slowly polymerized. These components have demonstrated synergistic healing processes $[1,8,11]$, mainly due to the releasing of cytokines $[1,8-10,12]$ released from the three-dimensional fibrin matrix which is continuously reabsorbed, inducing a greater response in the healing process [13].

Afterward, researchers sought to produce an even better membrane with greater biological properties, using the low-speed centrifugation concept (LSCC). The evidence that protocols with reduction of the centrifugation force allow a greater and better distribution of cells of interest for the effectiveness of PRF in tissue regeneration, which resulted in the production of AdvancedPlatelet Rich Fibrin $\left(\mathrm{A}-\mathrm{PRF}^{\circ}\right)[12,14]$. This protocol was conceived to optimize the properties of the clot produced by the L-PRF technique to achieve a more appropriate scaffold with an even population of cells [7] and also containing greater numbers of white blood cells (neutrophils, macrophages, B and $\mathrm{T}$ lymphocytes) [13, 15]. Since then, PRF has been heavily applied in the dentistry and medical fields $[7,12,16]$.

The third generation proposed a modification, introducing concentrated growth factors (CGF) $[17,18]$ changing the centrifugation speed, from $2400 \mathrm{rpm}$ to 3000 rpm, and the centrifugation periods. Characterized by containing abundant growth factors in its rigid fibrin [19], yielding results in speeding up the proliferation and differentiation of cells [20].

However, the preparation protocols of A-PRF and CGF are similar and share the same principle in clot formation. They are not distinguishable either macro or microscopically, and to the present date, there have not been found any significant differences between them [19].

Three-dimensional scaffolds (2nd and 3rd generations) allow a continuous release of cytokines and growth factors enhancing mainly the first period of tissue repairs, such as TGF (transforming growth factors), PDGF (platelet-derived growth factors), VEGF (vascular endothelial growth factors), IGF (insulin-like growth factors), and many others, enhancing the healing process $[3,15]$, throughout almost 10 days [7] regulating the inflammation and reducing the risk of infection [20]. In comparison, PRP (1st generation) is completely dissolved in 3 days releasing its growth factors in the first hours $[1,21]$.

In this evolutive perspective, L-PRF and A-PRF have been considered to have improved mechanical properties [1] but there is no direct comparison of the L-PRF and A-PRF properties. Khorshidi et al. [22] tested the mechanical properties of early L-PRF versus PRGF/Endoret membranes. Another study analyzed the addition of silver nanoparticles into L-PRF in a way to improve its mechanical characteristics [23]. Isobe et al. [19] developed a comparison between A-PRF and CGF evaluating the mechanical parameters and degradability. Both groups were almost identical. Nonetheless, the highlight has been given to A-PRF clots who display a higher concentration of growth factors, inducing a more significant effect on angiogenesis, and its characteristics will surely deliver a different resistance to the membrane [24].

Thus, there is a gap in the literature to landmark the evolutive process concerning the mechanical properties in specific the resistance to tensile strength which consequently may influence the time for membrane degradation. Furthermore, there is no direct comparison in the literature of these two protocols (L-PRF and A-PRF) and how these products behave mechanically, this research may be a tool to further extend the knowledge on how these materials will interact in a surgical wound and help 
in clarifying what results should the clinician expect to achieve.

Therefore, this research aimed to evaluate and compare the value of mechanical resistance to the tension of PRF membranes produced with different protocols (LPRF and A-PRF). The hypothesis of this study was to verify the membrane with better tensile properties and be able to suggest a product more able to withstand the stress when applied in surgeries.

\section{Materials and methods}

\section{Blood collection and membrane preparation}

The design of this study and its consent forms for all procedures performed followed the Helsinki Declaration of 1975 as revised in 2013, and the study started after approval by the Ethics Committee (number 522020). Then, the blood was collected from a single healthy person (M.A.N.C.P.) in different days avoiding variations, under restricted food starting 1 day prior to the procedure, with no history of anticoagulant usage or any disease, into 9-mL sterile glass-coated plastic tubes, red top blood collection tubes (Intralock $\odot$, USA) (Fig. 1a), under standard ambient conditions at $20 \pm 2{ }^{\circ} \mathrm{C}$. The study was performed in collaboration with the Centre for Mechanical Technology and Automation (TEMA) of the University of Aveiro (Portugal).

L-PRF membranes were prepared according to the original technique with centrifugation at 2700 revolutions per minute (rpm), $408 \mathrm{~g}$, for $12 \mathrm{~min}$ with the IntraSpin ${ }^{\mathrm{nm}}$ centrifugation device $\left(33^{\circ}\right.$ rotor angulation, $50 \mathrm{~mm}$ radius at the middle of the tube, $80 \mathrm{~mm}$ at the maximum, and $40 \mathrm{~mm}$ maximum, and $40 \mathrm{~mm}$ at the minimum) (IntraLock, Boca Raton, FL, USA) [23] (Fig. 1b). For the A-PRF membrane preparation, both the centrifugation time and speed are different, following the original values for this technique $1500 \mathrm{rpm}(126 \mathrm{~g})$ for $14 \mathrm{~min}$ [12, 24].

After $12 \mathrm{~min}$ of centrifuging for L-PRF and $14 \mathrm{~min}$ for A-PRF, beyond the membranes rested inside the box for $20 \mathrm{~min}$ before performing procedures [25], the clots are ready (13 membranes for each group, totaling $n=26$ ). Thus, the fibrin clots were taken out of the tubes and separated from the red blood cells. Following membrane preparation, fibrin clots were placed in the Xpression box (IntraLock $\odot$ ) for gentle compression by gravity and slightly pressing until to close completely the metal cover (Fig. 1c), following the recommendation of the manufacturer. Five minutes later, the L-PRF and A-PRF membranes are ready for use (Fig. 1d).

\section{Tensile assay}

Before the traction test, the membranes were standardized and measured using a WHO Periodontal probe and cut in a rectangular shape in which the short ends measured $5 \mathrm{~mm}$ of length and $1 \mathrm{~mm}$ of height each, only one per membrane. The tensile test was performed using a universal testing machine (Shimadzu MMT-101 N equipment, Shimadzu Corporation, Japan) [22, 26] (Fig. 2a), where the PRF membranes were conducted through a surgical tweezer, to put both extremities of the membranes fixed in the tensile force apparatus. By applying divergent forces $(1 \mathrm{~mm}$ spacing between the claws of the equipment), the maximum traction was measured in 13 membranes for each protocol $(n=26)$ (Fig. 2b), until rupture [27]. The maximum value for traction using this equipment is set to $12 \mathrm{~mm}$.

The equipment worked with the same movements for all membranes. Likewise, the position of the equipment

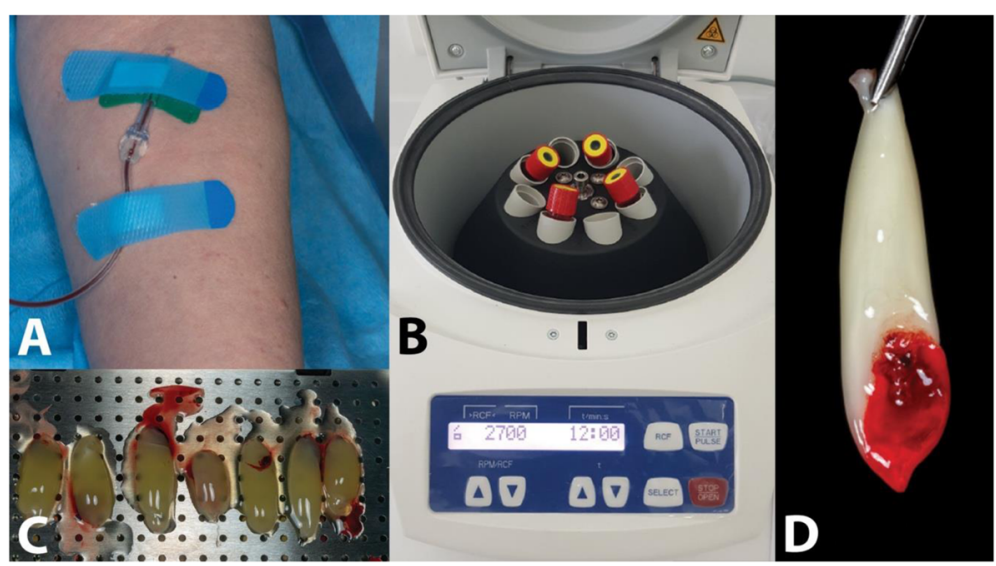

Fig. 1 PRF membrane production protocol. a Blood harvesting. b Blood centrifugation. c Clots collected from the centrifuged tubes and placed in the Xpression box kit. $\mathbf{d}$ Final PRF membrane obtained 


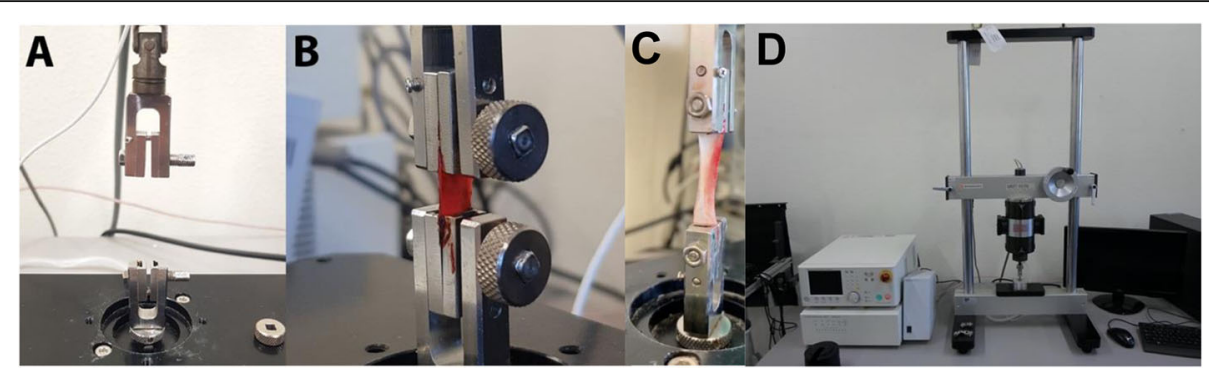

Fig. 2 Mechanical traction assay. a Equipment where all tests were performed. $\mathbf{b}$ Execution of the test in the L-PRF group. $\mathbf{c}$ In A-PRF group. $\mathbf{d}$ Equipment used to perform all mechanical tests, Shimadzu MMT-101 N (Shimadzu Corporation; Japan)

was similar according to the time of analysis, during the traction of the PRF. Therefore, the variable time was not considered for the study and it was not included. But, the variable resistance to tension (start of traction and end, rupture) were evaluated.

\section{Data and statistical analysis}

The force applied to the membrane per area of the section in the equipment's claws $\left(\mathrm{N} \mathrm{mm}^{-2}\right)$, and the traction of the membrane (percentage of deformation in comparison to the initial spacing between the claws, 1 $\mathrm{mm}$ ) were plotted for each membrane. With all the information needed, a graph was constructed to determine the maximum force that was applied until the membrane ruptured, giving us the maximum tensile strength.

Data was collected and transferred to Microsoft Excel (Microsoft()) and GraphPad Prism 7.0 where all statistical analysis was performed. All normality tests evaluated the data obtained. Values are presented as mean \pm SEM in the figure legends. Statistical comparisons included a two-sided unpaired $t$ test. A significant level of significance was obtained if the $p$ value was $\leq 0.05$. Moreover, it was verified the normal distribution of the means found (Normal Q-Q analysis).

\section{Results}

The traction evaluation was based on the quantification of the average traction obtained for each membrane tested and the maximum value detected upon the rupture of each membrane. A curve of the values obtained was registered to observe a possible correlation and comparison between the groups. This proved important not only to discover the maximum resistance of the membranes but also to understand if it would represent an actual statistically different average resistance. All data were analyzed and they were according to the normality (Table 1) what can be verified positive correlation with the normal distribution obtained (Fig. 3).

From the traction evaluation of $13 \mathrm{~L}-\mathrm{PRF}$ and $13 \mathrm{~A}$ PRF membranes, it was found that there was a significant statistical difference in the maximum traction with rupture and the average traction between the LPRF and A-PRF protocols (Fig. 4a, b). The traction test results had some variability within and between groups. All detailed data were demonstrated in Table 2 .

In reference to the average traction, A-PRF obtained a value of $0.0288 \mathrm{~N} \mathrm{~mm}^{-2}$ and L-PRF $0.0192 \mathrm{~N} \mathrm{~mm}^{-2}(p \leq$ 0.05 using unpaired $t$ test) and for maximal traction, APRF obtained $0.0752 \mathrm{~N} \mathrm{~mm}^{-2}$ and L-PRF $0.0425 \mathrm{~N}$ $\mathrm{mm}^{-2}(p<0.001$ using unpaired $t$ test) (Fig. 5a, b).

\section{Discussion}

This study intended to fill a lack of scientific knowledge about the APC membranes' mechanical properties, evaluating specifically the resistance to tension until rupture between L-PRF and A-PRF. It is an important question, especially regarding the degradation time which may be different from a tougher membrane. If the biomaterial is rapidly reabsorbed, it may lead to insufficient tissue regeneration [28]. Also, harvesting the blood of only one participant avoided any interference or bias.

In Medicine, these membranes can be applied in refractory leg ulcers associated or not with osteomyelitis [29], improving wound healing and closure. In Dentistry, more specifically in periodontal surgery, questions have emerged about the use of PRF membranes with favorable results. Studies have suggested it as a possible substitute for a connective tissue graft, which is still considered the "gold standard" for soft tissue surgery $[16,30]$. In oral surgery, favorable results have been found for the insertion of membranes inside of fresh

Table 1 Test for normal distribution

\begin{tabular}{lll}
\hline Number of membranes & L-PRF & A-PRF \\
Normality tests & $\mathbf{1 3}$ & $\mathbf{1 3}$ \\
\hline $\begin{array}{l}\boldsymbol{D}^{\prime} \text { Agostino and Pearson test } \\
\quad P \text { value }\end{array}$ & 0.9763 & \\
$\quad$ Passed normality test (alpha $=0.05) ?$ & Yes & Yes \\
\hline
\end{tabular}




\section{Normal QQ plot - Mean}

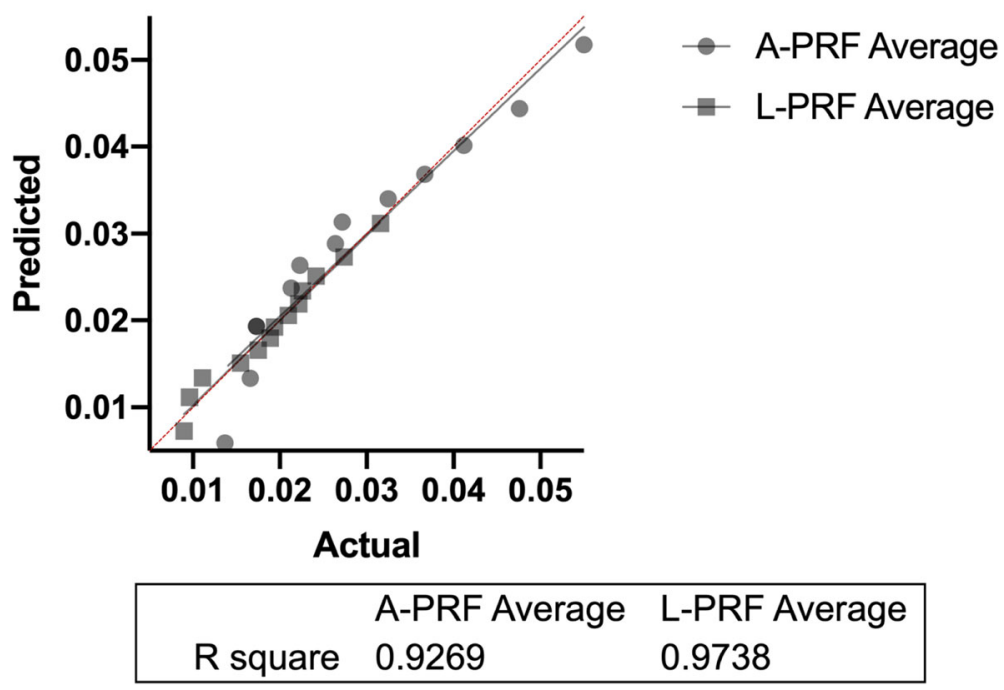

Fig. 3 Normal Q-Q plot. Correlation of the data with the normal distribution (line)

socket after extraction or using it in the treatment for bone lesions [31]. Furthermore, the use of a PRF membrane avoids a donor site which greatly decreases the postoperative discomfort [30].

An article evaluated the performance of APC associated with albumin [32] which could represent a possible improvement in its framework, modulating the fibrin network ultrastructure and permeability. Also, the material produced in this study showed to have higher biocompatibility, and possibly more durable with a greater thickness and resistance [32, 33]. However, the levels of released cytokines and growth factors were similar to those found for PRF; also, its degradation period is compatible with PRF extending to almost 10 days $[1,7]$. Being more difficult and expensive to produce this technique proves to be inferior to a PRF membrane.

This biodegradable material, APC, suffers degradation after its insertion in the surgical site, becoming necessary to know its resistance. Furthermore, freezing the membranes could be an alternative methodology to improve the characteristics of APC, at temperatures of $-20^{\circ} \mathrm{C}$, and thawing at $+4{ }^{\circ} \mathrm{C}$, which may help to decrease the rapid degradation, becoming a better biomaterial for clinical application [28]. Although it may be hard to control the correct temperature on the day of application, the use of a freezer with the desired settings may prove beneficial.

Another methodology was developed and deserves to be highlighted. It is known as the low-speed centrifugation concept (LSCC) which is used to produce A-PRF membranes. This concept is suggested to be the factor that greatly increases the resistance of the membranes produced with this protocol. This technique diminishes the cell pull-down by the $\mathrm{g}$ forces applied in the centrifugation, increasing the number of cells within the top layer of the fibrin matrix. This surely modifies the A-PRF's properties compared to L-PRF, which suffers much higher forces during the centrifugation, concentrating almost all cellular content at the bottom of the clot [24].

Controversially, although other techniques [28, 32] exist, the simplest way is to follow the protocols strictly using the correct centrifugation settings to obtain the correct membrane. Thus, the results obtained for L-PRF in this study (average of $0.02260 \mathrm{MPa}$ ) is in perfect agreement with the resistance of L-PRF published by Khorshidi et al. [22] $(0.20 \pm 0.06 \mathrm{MPa})$, but strangely, Ravi and Santhanakrishnan (2020) [26] found an extremely higher value for L-PRF $(290.076 \pm 5.68 \mathrm{MPa})$. Nonetheless, the same authors also found extremely high values for A-PRF $(362.565 \pm 5.15 \mathrm{MPa})$, differently than obtained in this study (average of $0.04130 \mathrm{MPa}$ ). However, this study may state that A-PRF had a higher resistance to traction than L-PRF similar to published by Ravi and Santhanakrishnan (2020) [26]; therefore, in this study, it was observed almost twice more in the average of resistance, with an extremely significant statistical difference. Concerning average traction, A-PRF also achieved a significant statistical difference compared to L-PRF. This fact is due to a looser structure with more interfibrous space with a lower crosslink and greater elasticity, beyond the better distribution of the content throughout the fibrin after using the LSCC, which 


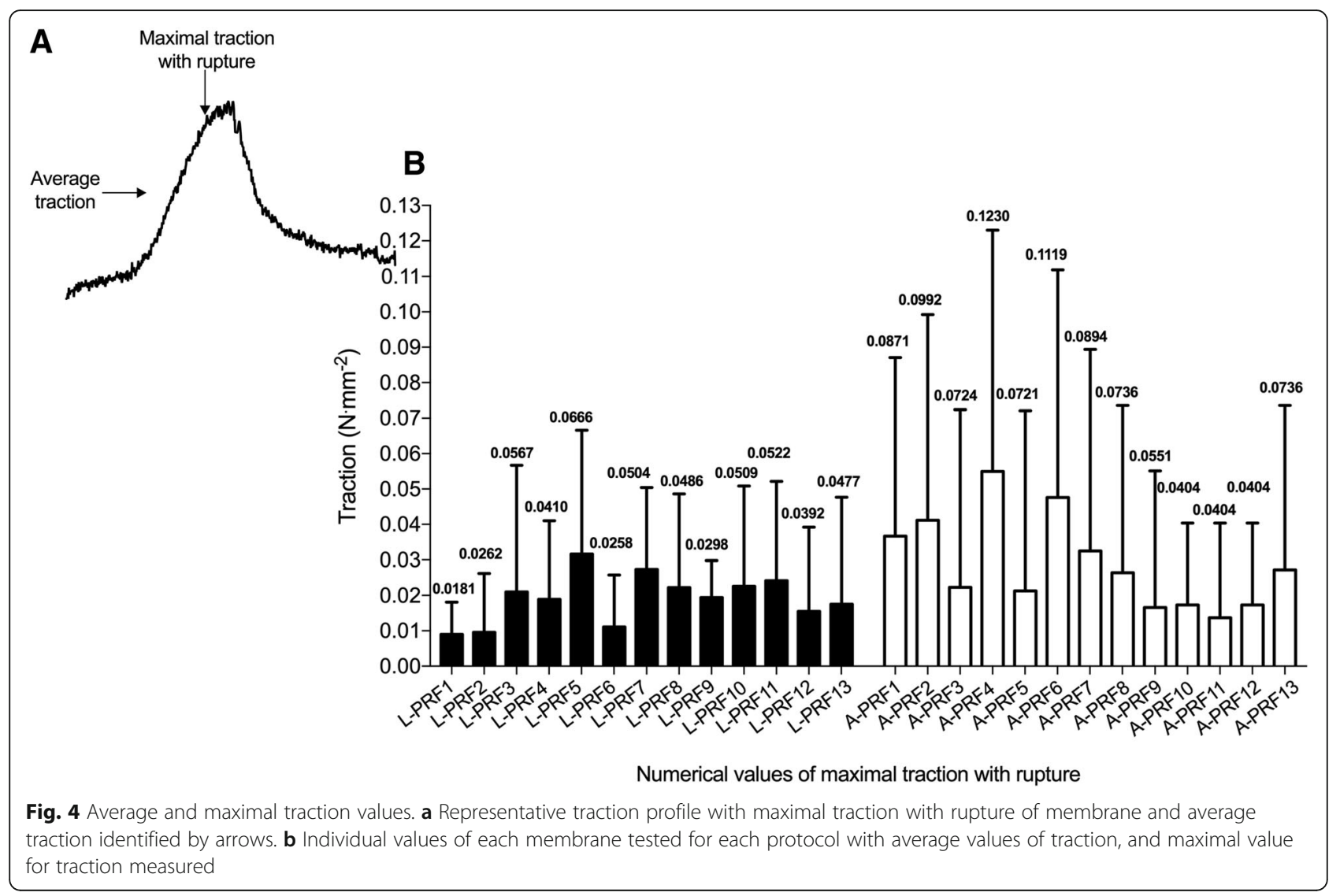

allowed a greater presence of neutrophil cells and platelets in the PRF $[12,34,35]$.

It was noticed that in the A-PRF group some membranes scored similarly, regarding the maximal traction. However, the average traction was different,

Table 2 Descriptive statistics of the traction data obtained

\begin{tabular}{lll}
\hline Average & \multicolumn{2}{l}{ Maximal limit } \\
\cline { 2 - 3 } & L-PRF & A-PRF \\
\hline Minimum & 0.009000 & 0.01370 \\
Maximum & 0.03160 & 0.05500 \\
Range & 0.02260 & 0.04130 \\
Geometric mean & 0.01802 & 0.02637 \\
95\% Cl of median & & \\
Actual confidence level & $97.75 \%$ & $97.75 \%$ \\
Lower confidence limit & 0.01110 & 0.01730 \\
Upper confidence limit & 0.02420 & 0.04120 \\
Mean, SD, and SE & & \\
$\quad$ Mean & 0.01923 & 0.02885 \\
Std. deviation (SD) & 0.006760 & 0.01297 \\
Std. error of mean (SE) & 0.001875 & 0.003597 \\
95\% Cl of mean & & 0.02102 \\
$\quad$ Lower & 0.01515 & 0.03669 \\
\hline Upper & 0.02332 & \\
\hline
\end{tabular}

indicating that the structure of each membrane was slightly different, even with the same donator and time of the blood collection. In the L-PRF protocol, the same happened but with little difference between the values. This indicates that there is a large variation to be expected when producing APC membranes, and one may not achieve the highest traction possible. Regarding the experimental time, it was observed for L-PRF the mean of $72.33 \mathrm{~s}(\mathrm{SD} \pm 41.84 \mathrm{~s}$ ) with a maximum time of $180.40 \mathrm{~s}$; and for A-PRF, the mean of $74.48 \mathrm{~s}$ (SD $\pm 43.15 \mathrm{~s}$ ) with maximum period of $180.50 \mathrm{~s}$. For period analyzed to achieve rupture, for L-PRF group was found the average of $74.73 \mathrm{~s}$ (minimum $34.60 \mathrm{~s}$ and maximum $130.40 \mathrm{~s}$ ); while for A = PRF group, the average was $132.24 \mathrm{~s}$, almost twice the L-PRF group, with minimum $81.50 \mathrm{~s}$ and maximum $178.50 \mathrm{~s}$.

It was known that A-PRF had a higher concentration of growth factors within its fibrin matrix, increasing the tissue regeneration rate when applied in a surgical wound [12]. This fact allied to the higher maximal traction and average traction appears to make it a more suitable material for regeneration than L-PRF. Indeed, the LSCC has produced membranes with a more even distribution of cells throughout the fibrin clot and a more mechanically resistant membrane. This reveals that, 


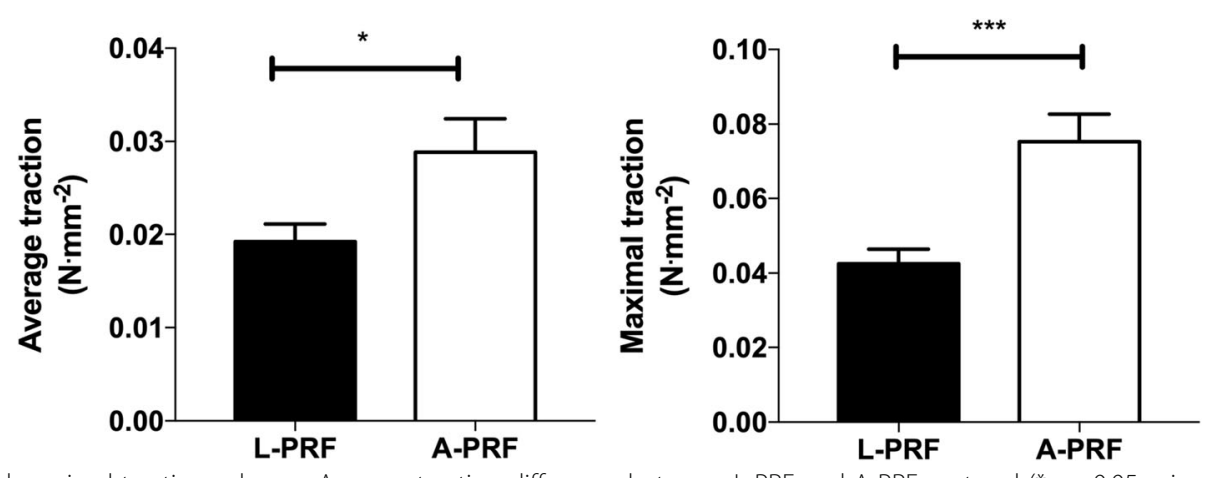

Fig. 5 Average and maximal traction values. a Average traction difference between L-PRF and A-PRF protocol $\left({ }^{*} p<0.05\right.$ using unpaired $t$ test $n$ $=13)$. $\mathbf{b}$ Maximal traction difference between L-PRF and A-PRF protocol ${ }^{* * *} p<0.001$ using unpaired t test $\left.n=13\right)$

when applied in multiple situations, A-PRF may be more effective.

Regarding the only one individual included in this study, this strategy was applied to avoid any type of bias. The literature [36-38] has reported platelet alterations associated with many systemic conditions and the use of drugs, which was observed and controlled in this study.

\section{Conclusion}

Through this pilot study, it was possible to conclude that there was significantly higher resistance to traction in membranes produced with the A-PRF compared to the L-PRF protocol, suggesting more handleability when applied clinically, such as in surgeries, resisting receiving a suture. Nevertheless, it is necessary that more studies with major samples and distinguishing gender and age.

\begin{abstract}
Abbreviations
APC: Autologous platelet concentrate; A-PRF: Advanced-platelet-rich fibrin; CGF: Concentrated growth factors; Cl: Confidence interval;

EDTA: Ethylenediaminetetraacetic acid; IGF: Insulin-like growth factors; LPRF: Leucocyte- and platelet-rich fibrin; LSCC: Low-speed centrifugation concept; PDGF: Platelet-derived growth factors; PRF: Platelet-rich fibrin; PRGF: Platelet-rich growth factors; PRP: Platelet-rich plasma; SD: Standard deviation; SE: Standard error; SEM: Standard error of the mean;

TGF: Transforming growth factors; VEGF: Vascular endothelial growth factors; WHO: World Health Organization
\end{abstract}

\section{Acknowledgements}

For all teamwork from the TEMA laboratory (University of Aveiro).

\section{Authors' contributions}

M.A.N.C.P., N.B.M.S., and G.V.O.F. were responsible for the conduction of the experiment and data acquisition, conceptualized the study, analyzed the data, wrote the original draft, and edited the manuscript final article. A.M.G.C. adjusted the mechanical test and had critically discussed the results. The author(s) read and approved the final manuscript.

\section{Funding}

The authors declare that this study was developed with their own resources by the authors.

Availability of data and materials All data are included in the article.
Ethics approval and consent to participate

Prior to the beginning, the study was approved by the local Ethics Committee (number 522020), at the Catholic University of Portugal.

\section{Consent for publication}

All authors, before submitting the article to the International Journal of Implant Dentistry, agreed to submit and transfer all publication rights to the International Journal of Implant Dentistry including all submitted materials in case of acceptance.

\section{Competing interests}

Martim de Almeida Nóbrega Correia Pascoal, Nuno Bernardo Malta dos Santos, António Manuel Godinho Completo, and Gustavo Vicentis de Oliveira Fernandes declare no competing interests associated with this study.

\section{Author details}

${ }^{1}$ Integrated Master in Dental Medicine, Faculty of Dental Medicine, Universidade Católica Portuguesa, Viseu, Portugal. ${ }^{2}$ Periodontics Department, Center for Interdisciplinary Research in Health (CIIS), Faculty of Dental Medicine, Universidade Católica Portuguesa, Viseu, Portugal. ${ }^{3}$ TEMA, Universidade de Aveiro, Aveiro, Portugal. ${ }^{4}$ Implantology and Biomaterials Department, Faculty of Dental Medicine, Universidade Católica Portuguesa, Quinta da Alagoa Ave., 225 - 1 DT, 3500-606 Viseu, Portugal.

Received: 15 September 2020 Accepted: 17 December 2020

Published online: 15 January 2021

References

1. Dohan DM, Choukroun J, Diss A, Dohan SL, Dohan AJ, Mouhyi J, Gogly B. Platelet-rich fibrin (PRF): a second-generation platelet concentrate. Part I: Technological concepts and evolution. Oral Surg Oral Med Oral Pathol Oral Radiol Endod. 2006;101(3):e37-44.

2. Dohan Ehrenfest DM, Rasmusson L, Albrektsson T. Classification of platelet concentrates: from pure platelet-rich plasma (P-PRP) to leucocyte- and platelet-rich fibrin (L-PRF). Trends Biotechnol. 2009;27(3):158-67.

3. Marx RE, Carlson ER, Eichstaedt RM, Schimmele SR, Strauss JE, Georgeff KR Platelet rich plasma: growth factor enhancement for bone grafts. Oral Surg Oral Med Oral Pathol Oral Radiol Endod. 1998:85(6):368-46.

4. Whitman H, Berry L, Green M. Platelet gel: an autologous alternative to fibrin glue with applications in oral and maxillofacial surgery. J Oral Maxillofac Surg. 1997;55(11):1294-9.

5. Anitua E, Sánchez M, Orive G, Andía I. The potential impact of the preparation rich in growth factors (PRGF) in different medical fields. Biomaterials. 2007;28(31):4551-60.

6. Dragonas P, Schiavo JH, Avila-Ortiz G, Palaiologou A, Katsaros T. Plasma rich in growth factors (PRGF) in intraoral bone grafting procedures: a systematic review. J Craniomaxillofac Surg. 2019;47(3):443-53.

7. Miron RJ, Zucchelli G, Pikos MA, Salama M, Lee S, Guillemette V, et al. Use of platelet-rich fibrin in regenerative dentistry: a systematic review. Clin Oral Investig. 2017;21(6):1913-27. 
8. Dohan DM, Choukroun J, Diss A, Dohan SL, Dohan AJJ, Mouhyi J, Gogly B. Platelet-rich fibrin (PRF): a second-generation platelet concentrate. Part II: Platelet-related biologic features. Oral Surg Oral Med Oral Pathol Oral Radiol Endod. 2006:101(3):e45-50.

9. Dohan DM, Choukroun J, Diss A, Dohan SL, Dohan AJJ, Mouhyi J, Gogly B. Platelet-rich fibrin (PRF): a second-generation platelet concentrate. Part III: Leucocyte activation: A new feature for platelet concentrates? Oral Surg Oral Med Oral Pathol Oral Radiol Endod. 2006;101(3):e51-5.

10. Choukroun J. An opportunity in paroimplantology: PRF. Implantodontie. 2001:42:55-62.

11. Borie E, Oliví DG, Orsi IA, Garlet K, Weber B, Beltrán V, Fuentes R. Platelet-rich fibrin application in dentistry: a literature review. Int J Clin Exp Med. 2015; 8(5):7922-9.

12. Ghanaati S, Booms P, Orlowska A, Kubesch A, Lorenz J, Rutkowski J, et al. Advanced platelet-rich fibrin: a new concept for cell-based tissue engineering by means of inflammatory cells. J Oral Implant. 2014;40(6):67989.

13. Verma UP, Yadav RK, Dixit M, Gupta A. Platelet-rich fibrin: a paradigm in periodontal therapy - a systematic review. J Int Soc Prevent Communit Dent. 2017;7:227-33.

14. Choukroun J, Ghanaati S. Reduction of relative centrifugation force within injectable platelet-rich-fibrin (PRF) concentrates advances patients' own inflammatory cells, platelets and growth factors: the first introduction to the low speed centrifugation concept. Eur J Trauma Emerg Surg. 2018;44(1):8795.

15. Steenvoorde P, van Doorn LP, Naves C, Oskam J. Use of autologous platelet-rich fibrin on hard-to-heal wounds. J Wound Care. 2008;17(2):60-3.

16. Castro AB, Meschi N, Temmerman A, Pinto N, Lambrechts $P$, Teughels $W$, Quirynen M. Regenerative potential of leucocyte- and platelet-rich fibrin. Part A: intra-bony defects, furcation defects and periodontal plastic surgery. A systematic review and meta-analysis. J Clin Periodontol. 2017;44:67-82.

17. Rodella LF, Favero G, Boninsegna R, Labanca M, Scari G, Sacco L, et al. Growth factors, CD34 positive cells, and fibrin network analysis in concentrated growth factors fraction. Microsc Res Tech. 2011;74:772-7.

18. Takeda Y, Katsutoshi K, Matsuzaka K, Inoue T. The effect of concentrated growth factor on rat bone marrow cells in vitro and on calvarial bone healing in vivo. Int J Oral Maxillofac Implants. 2015;30:1187-96.

19. Isobe K, Watanebe T, Kawabata H, Kitamura Y, Okudera T, Okudera H, et al. Mechanical and degradation properties of advanced platelet-rich fibrin (APRF), concentrated growth factors (CGF), and platelet-poor plasma-derived fibrin (PPTF). Int J Implant Dent. 2017;3(1):17.

20. Kaval B, Renaud DE, Scott DA, Buduneli N. The role of smoking and gingival crevicular fluid markers on coronally advanced flap outcomes. J Periodontol. 2014;85:395-405.

21. Ehrenfest DMD, Bielecki T, Jimbo R, Barbé G, Del Corso M, Inchingolo F, et al. Do the fibrin architecture and leukocyte content influence the growth factor release of platelet concentrates? An evidence-based answer comparing a pure platelet-rich plasma (P-PRP) gel and a leukocyte- and platelet-rich fibrin (L-PRF). Curr Pharm Biotechnol. 2012;13(7):1145-52.

22. Khorshidi H, Raoofi S, Bagheri R, Banihashemi H. Comparison of the mechanical properties of early leukocyte- and platelet-rich fibrin versus PRGF/Endoret membranes. Int J Dent. 2016;2016:1849207.

23. Khorshidi H, Haddadi P, Raoofi S, Badiee P, Nazhvani AD. Does adding silver nanoparticles to leukocyte- and platelet-rich fibrin improve its properties? Biomed Res Int. 2018;2018:8515829.

24. Miron RJ, Choukroun J. Platelet rich fibrin in regenerative dentistry: biological background and clinical indications: biological background and clinical indications. Oxford: Wiley; 2017.

25. Lourenço ES, Alves GG, Barbosa RL, Spiegel CN, Mello-Machado RC, AlMaawi S, Ghanaati S, Mourão CFAB. Effects of rotor angle and time after centrifugation on the biological in vitro properties of platelet rich fibrin membranes. J Biomed Mat Res Part B Appl Mat. 2020;109(1):60-8.

26. Ravi $S$, Santhanakrishnan M. Mechanical, chemical, structural analysis and comparative release of PDGF-AA from L-PRF, A-PRF and T-PRF - an in vitro study. Biomat Res. 2020;24:16.

27. Hawley S. Particular requirements for plastics. In: Brown R, editor. Handbookof polymer testing. New York: Marcel Dekker Inc; 1999. p. 313.

28. Kardos D, Hornyák I, Simon M, Hinsenkamp A, Marschall B, Várdai R, et al. Biological and mechanical properties of platelet-rich fibrin membranes after thermal manipulation and preparation in a single-syringe closed system. Int J Mol Sci. 2018;19(11):3433.
29. Pinto NR, Ubilla M, Zamora Y, Del Rio V, Dohan Ehrenfest DM, Quirynen M Leucocyte- and platelet-rich fibrin (L-PRF) as a regenerative medicine strategy for the treatment of refractory leg ulcers: a prospective cohort study. Platelets. 2017:1-8.

30. Li R, Liu Y, Xu T, Zhao H, Hou J, Wu Y, Zhang D. The additional effect of autologous platelet concentrates to coronally advanced flap in the treatment of gingival recessions: a systematic review and meta-analysis. Biomed Res Int. 2019;2019:2587245.

31. Canellas JVDS, Medeiros PJD, Figueredo CMDS, Fischer RG, Ritto FG. Plateletrich fibrin in oral surgical procedures: a systematic review and meta-analysis. Int J Oral Maxillofac Surg. 2019:48(3):395-414.

32. Barros Mourão CF, Gheno E, Lourenço ES, Barbosa R, Kurtzman GM, Javid K, et al. Characterization of a new membrane from concentrated growth factors associated with denaturized Albumin (Alb-CGF) for clinical applications: a preliminary study. Int J Growth Factors Stem Cells Dent. 2018;1:64-9.

33. van Gelder JM, Nair CH, Dhall DP. Colloid determination of fibrin network permeability. Blood Coagul Fibrinolysis. 1996;7:747-60.

34. Fujioka-Kobayashi M, Miron RJ, Hernandez M, Kandalam U, Zhang Y, Choukroun J. Optimized platelet-rich fibrin with the low-speed concept: growth factor release, biocompatibility, and cellular response. J Periodontol. 2017;88(1):112-21.

35. Caymaz MG, Uyanik LO. Comparison of the effect of advanced platelet-rich fibrin and leukocyte- and platelet-rich fibrin on outcomes after removal of impacted mandibular third molar: a randomized split-mouth study. Niger J Clin Pract. 2019;22(4):546-52.

36. Geisler T, Anders N, Paterok M, Langer H, Stellos K, Lindemann S, Herdeg C, May AE, Gawaz M. Platelet response to clopidogrel is attenuated in diabetic patients undergoing coronary stent implantation. Diabetes Care. 2007;30: 372-4.

37. Angiollo DJ, Fernandez-Ortiz A, Bernardo E, Ramírez C, Sabaté M, JimenezQuevedo P, Hernández R, Moreno R, Escaned J, Alfonso F, Bañuelos C, Costa MA, Bass TA, Macaya C. Clopidogrel withdrawal is associated with proinflammatory and prothrombotic effects in patients with diabetes and coronary artery disease. Diabetes. 2006:55:780-4.

38. Angiolillo DJ, Badimon JJ, Saucedo JF, Frelinger AL, Michelson AD, Jakubowski JA, Zhu B, Ojeh CK, Baker BA, Effron MB. A pharmacodynamic comparison of prasugrel vs. high-dose clopidogrel in patients with type 2 diabetes mellitus and coronary artery disease: results of the optimizing antiplatelet therapy in diabetes mellitus (OPTIMUS)-3 trial. Eur Heart J. 2011;32: 838-46.

\section{Publisher's Note}

Springer Nature remains neutral with regard to jurisdictional claims in published maps and institutional affiliations.

\section{Submit your manuscript to a SpringerOpen ${ }^{\circ}$ journal and benefit from:}

- Convenient online submission

- Rigorous peer review

- Open access: articles freely available online

- High visibility within the field

- Retaining the copyright to your article

Submit your next manuscript at $\boldsymbol{\nabla}$ springeropen.com 